\title{
The effect of obesity and dietary habits on oxidative stress in Hashimoto's thyroiditis
}

\author{
Maria Giannakou1', Katerina Saltiki ${ }^{1,2}$, Emily Mantzou², Eleni Loukari², Georgios Philippou², \\ Konstantinos Terzidis², Charalampos Stavrianos², Miltiades Kyprianou', Theodora Psaltopoulou ${ }^{3}$, \\ Kalliopi Karatzi ${ }^{4}$ and Maria Alevizaki ${ }^{1,2}$
}

${ }^{1}$ Endocrine Unit, Department Med Therapeutics, Alexandra Hospital, School of Medicine, National Kapodistrian University, Athens, Greece 2Department of Endocrinology and Metabolism, Athens University School of Medicine, Athens, Greece

${ }^{3}$ Department of Hygiene, Epidemiology and Medical Statistics, School of Medicine, National Kapodistrian University, Athens, Greece ${ }^{4}$ Department of Nutrition and Dietetics, School of Health Science and Education, Harokopio University of Athens, Athens, Greece

Correspondence should be addressed to M Alevizaki: mani@otenet.gr

\begin{abstract}
Objective: Increased oxidative stress has been described in patients with Hashimoto's thyroiditis (HT). The aim of the present study was to investigate whether high oxidative stress is further influenced by obesity and dietary habits in euthyroid women with HT. Methods: Two hundred eighteen consecutive euthyroid women with HT were studied and separated in two groups; 102 with thyroxine replacement and 114 without. For the evaluation of oxidative stress, total lipid peroxide levels in serum (TOS) were measured and recoded as 'high TOS' vs 'medium/low TOS'. The type of food and consumption frequency were recorded. Two binary variables were considered; normal vs low fruit consumption and daily vs sporadic vegetable consumption.

Results: 'High TOS' was more frequent in women under thyroxine replacement $(31.4 \%$ vs $14.7 \%, \mathrm{OR}=2.7,95 \% \mathrm{Cl}: 1.4-5.2$ ). The prevalence of 'high TOS' was higher among overweight/obese women compared to women with normal BMI (30.4\% vs $12.5 \%$, $\mathrm{OR}=3.1,95 \% \mathrm{Cl}: 1.5-6.4)$. Low fruit consumption was associated with increased 'high TOS' prevalence (30.6\% vs $12.9 \%$, OR $=3.0,95 \% \mathrm{Cl}: 1.4-6.2)$. Sporadic vegetable consumption was associated with increased 'high TOS' prevalence compared to daily consumption $(29.9 \%$ vs $13.5 \%, \mathrm{OR}=2.7,95 \% \mathrm{Cl}: 1.3-5.7)$. The examined risk factors were independent and additive in their effect on TOS. At least three risk factors had to be concomitantly present for the likelihood of 'high TOS' to be significantly elevated.

Conclusions: Oxidative stress is increased in women with HT under thyroxine replacement. Nevertheless, normal BMI, daily fruit and vegetable consumption, all contribute in maintaining oxidative stress at low levels.
\end{abstract}

\section{Introduction}

Reduction-oxidation (redox) processes are a fundamental part of human metabolism $(1,2)$. Oxidants are a large group of reactive species including both free-radicals and nonradicals (i.e. reactive oxygen species, reactive nitrogen species, reactive chlorine/bromine species, reactive sulfur species) $(1,2)$. At low/moderate concentrations oxidants are necessary for normal cell functions such as signaling mechanisms, defense against infectious agents and the process of mitosis $(1,2,3,4)$. On the other hand, at high concentrations, oxidants react with biomolecules and alter their functions $(3,4)$. These reactions can lead to DNA modification, lipid peroxidation, disturbance of the lipid membrane arrangement, fragmentation of the peptide chain and alteration of the electrical charge of proteins http://www.endocrineconnections.org https://doi.org/10.1530/EC-18-0272
() 2018 The authors Published by Bioscientifica Ltd

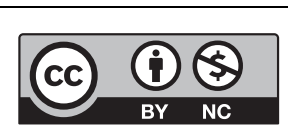

This work is licensed under a Creative Commons Attribution-NonCommercial 4.0 International License. 
$(3,4)$. The harmful effect of oxidants is counterbalanced by a variety of antioxidants, both enzymatic (i.e. catalases, superoxide dismutases, glutathione peroxidases, thioredoxin system) and nonenzymatic (i.e. b-carotene, glutathione vitamin E, vitamin C, vitamin A) $(1,2,3,4)$. Disturbance of the balance between oxidants and antioxidants in favor of the oxidants results in oxidative stress $(1,2,3,4)$.

Environmental factors and lifestyle can affect the balance between oxidants and antioxidants and oxidative stress accordingly $(4,5,6,7,8,9,10,11)$. Exposure to exogenous sources of oxidants such as cigarette smoke, ozone, ionizing radiation and heavy metal ions promotes oxidative stress production $(4,5)$. Diet and physical activity both have an impact on oxidative stress levels $(5,6,7,8,9,10,11)$. Frequent consumption of food rich in antioxidants such as fruit and vegetables reinforce antioxidant defense mechanisms $(6,7,8)$, whereas alcohol abuse leads to overproduction of oxidants (5). Concerning physical activity, regular moderate-to-high-intensity exercise contributes to antioxidant defense system (9). Nevertheless, both exhausting exercise and sedentary life lead to oxidative stress $(10,11)$.

The balance between oxidants and antioxidants is critical for the proper function of the thyroid gland $(12,13,14,15)$. Reactive oxygen species are present in thyroid tissue and are necessary for the physiological process of thyroid hormone synthesis $(12,13,14,15)$. To control the damage from reactive oxygen species, thyroid cells are equipped with antioxidant enzymes (superoxide dismutases, catalase and glutathione peroxidases) $(12,13$, $14,15)$. The role of oxidative stress in thyroid diseases has been the object of many studies $(16,17,18,19,20$, $21,22,23,24,25,26)$. High oxidative stress is involved in the pathogenesis of thyroid cancer $(16,17)$. Moreover, increased oxidative stress levels have been described in patients with Grave's disease $(18,19)$. In the same direction, studies among patients with HT have shown increased oxidants and decreased antioxidants' levels in these patients $(20,21,22,23,24,25,26)$.

Hashimoto's thyroiditis (HT) is the most common autoimmune thyroid disease and it affects people of any age with an increased incidence in middle-aged women $(27,28)$. Both genetic and environmental factors are implicated in the pathogenesis and the development of this disease $(29,30,31)$. Concerning oxidative stress in patients with HT, it is interesting to note that, despite the fact that the oxidative stress indices used varied, all studies reported increased oxidative stress levels $(20,21$, $22,23,24,25,26)$. Moreover, high oxidative stress was

$$
\text { http://www.endocrineconnections.org }
$$

present irrespective of the thyroid functional status euthyroidism $(20,21,22)$, subclinical hypothyroidism $(23,24,26)$ or overt hypothyroidism $(23,24,25,26)$. Studies evaluating the effect of thyroxine replacement therapy in newly diagnosed hypothyroid HT patients showed an improvement in the oxidative status of these patients when they became euthyroid $(32,33)$. Recent studies showed that high oxidative stress is associated with the severity and the progression of HT from euthyroidism to overt hypothyroidism $(23,34,35)$. The aim of the present study was to investigate whether high oxidative stress is further influenced by obesity and dietary habits in euthyroid women with Hashimoto thyroiditis.

\section{Materials and methods}

This cross-sectional study was conducted in Greece; it involved 218 consecutive euthyroid women with mean age $46.0 \pm 12.7$ years (range 19-69 years). All women were examined as outpatients at the Department of Endocrinology and Metabolism of Athens University School of Medicine from November 2010 to May 2014. The Institutional Ethics Committee of Athens University School of Medicine (Alexandra's Hospital Scientific Committee, 13/7/2012, protocol number 9468) approved this investigation and all patients were informed and gave consent to participate in the study. All women had Hashimoto's thyroiditis and had been diagnosed at least 6 months before entering the study. All participants were euthyroid (FT4: 9-20.5 pmol/L, TSH: 0.4-4.0 $\mu \mathrm{IU} / \mathrm{mL}$, T3: $0.7-1.8 \mathrm{ng} / \mathrm{mL}$ ), had hypoechogenic pattern in the ultrasound and at least one of thyroid autoantibodies was positive (anti-Tg $\geq 30 \mathrm{U} / \mathrm{L}$, anti-TPO $\geq 40 \mathrm{U} / \mathrm{L}$ ). None of them was pregnant (within the past 6 months) or breast-feeding at the time of the study and none of them was consuming vitamin supplements. First- and seconddegree relatives of those already enrolled in the study, who had HT, were excluded. Information about height, weight, waist and hip measurements were collected and waist-to-hip ratio and BMI were calculated for all participants. Clinical and demographic data were recorded and a detailed medical and family history was taken for all women. Thyroid volume and the presence of clinical goiter were evaluated through ultrasound and clinical examination. Based on World Health Organization's classification, women with BMI from 18.5 to $25 \mathrm{~kg} / \mathrm{m}^{2}$ were defined as normal weight, women with BMI from 25 to $30 \mathrm{~kg} / \mathrm{m}^{2}$ as overweight and women with BMI $>30 \mathrm{~kg} / \mathrm{m}^{2}$ as obese (36). Depending on thyroxine replacement

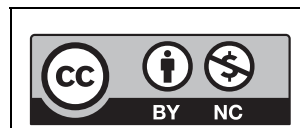

This work is licensed under a Creative Commons Attribution-NonCommercial 4.0 International License. 
therapy, women were classified into two groups. The first group consisted of 102 women on thyroxine replacement (treatment group), while the remaining 114 women did not receive thyroxine treatment and belonged to the no treatment group.

Thyroid function tests were performed for all patients. Blood samples were obtained by venipuncture between 08:00 and 09:00 $\mathrm{h}$ fasting. The specimens were centrifuged, and the serum was kept frozen at $-20^{\circ} \mathrm{C}$ until analyses. Serum TSH, free thyroxine (FT4), triiodothyronine (T3) and anti-thyroid antibodies (anti-TPO, anti-TG) were estimated by using chemiluminescence immunometric assays with the DPC Immulite 2000 (Siemens). Reference range was TSH: $0.4-4.0 \mu \mathrm{IU} / \mathrm{mL}, \mathrm{FT} 4: 9-20.5 \mathrm{pmol} / \mathrm{L}$, T3: $0.7-1.8 \mathrm{ng} / \mathrm{mL}$, anti-TPO $<30 \mathrm{U} / \mathrm{L}$, anti-TG $<40 \mathrm{U} / \mathrm{L}$.

For evaluation of the oxidative stress, total lipid peroxide levels in serum (TOS) were measured by using the PerOx-(TOS/TOC) kit (photometric test system for the determination of the total oxidative status/capacity - TOS/TOC - by Immundiagnostics) as previously reported $(37,38)$. The PerOx-(TOS/TOC) kit defines TOS values $<180 \mu \mathrm{mol} / \mathrm{L}$ as low oxidative stress, TOS values $180-310 \mu \mathrm{mol} / \mathrm{L}$ as moderate oxidative stress and TOS values $>310 \mu \mathrm{mol} / \mathrm{L}$ as high oxidative stress. In a previous study using the PerOx-(TOS/TOC) kit in the same population, it was shown that TOS had significant ability to discriminate between the two HT groups (35). Further analysis showed that the cutoff value that offered the best tradeoff between sensitivity and specificity was $590 \mu \mathrm{mol} / \mathrm{L}$ (35). Based on these results, TOS values for the present study were recoded as 'high TOS' $(\geq 590 \mu \mathrm{mol} / \mathrm{L})$ vs 'medium/low TOS' $(<590 \mu \mathrm{mol} / \mathrm{L})$.

A semi-quantitative food frequency questionnaire was developed for this study based on the study of Tyrovolas et al. (39) with adjustments. The questionnaire was designed to measure the frequency of consumption of various food groups and beverage categories that are usually consumed in Greece (i.e. red meat, poultry, fish and seafood, milk, yogurt, eggs, cheese, fruits, dried fruit, nuts, vegetables, greens, salads, legumes, pasta, potatoes, cereals, olive oil, sweets, junk food, soft drinks, spirits, tea and coffee) during the previous month. The answers were given in six predefined options (never, rare, 1-3 times per month, 1-2 times per week, 3-5 times per week, daily and 'how many times per day'). As portion size, we used the reference portion size described in the study of Tyrovolas et al. (39); this was explained in detail to all participants before the filling of the questionnaire. Using open-ended questions, we collected more information about the type of fruit, vegetables, bread, cheese, coffee and tea that were usually consumed during the past month. Based on the antioxidant capacity of food $(40,41,42)$, all answers were evaluated for possible associations with oxidative stress. Two binary variables were considered - fruit consumption and vegetable consumption. The cut-off for fruit consumption was at least 14 portions weekly which equals to at least two portions daily and the groups were named accordingly, normal (more than 14 portions weekly/more than two portions daily) vs low fruit consumption (less than 14 portions weekly/less than two portions daily). The cut-off for vegetable consumption was at least seven portions weekly which equals to at least one portion daily and the groups were named accordingly, daily (more than seven portions weekly/more than one portion daily) vs sporadic vegetable consumption (less than seven portions weekly/less than one portion daily).

\section{Statistical analysis}

The primary outcome was the presence of 'high TOS' $(\geq 590 \mu \mathrm{mol} / \mathrm{L})$. There were four binary independent predictors (risk factors): thyroxine treatment (Yes vs No), BMI (overweight/obese vs normal), fruit consumption (less than two portions daily vs at least two portions daily) and vegetable consumption (less than one portion daily vs at least one portion daily). Concerning the fruit and vegetable consumption, the original six-level ordinal variables regarding the quantity and frequency of fruit and vegetable consumption, that were recorded in the questionnaire, were checked for the existence of a linearby-linear association with the presence of high TOS using the chi-square for trends statistic. Subsequently, they were transformed into binary, dichotomous variables based on ROC analysis of the variables on TOS levels that produced the cutoffs providing the best tradeoff between sensitivity and specificity. The association of TOS levels with thyroxine treatment, BMI and dietary habits was checked with $2 \times 2$ contingency tables reporting the OR with its associated $95 \%$ confidence intervals, followed by stepwise logistic regression models. The level of significance was set at 0.05 .

\section{Results}

Table 1 shows median values (plus interquartile ranges) for demographic, clinical and biochemical characteristics of the study population. All women were euthyroid at the time of the study. TOS levels were significantly higher in the treatment group in comparison to the no treatment

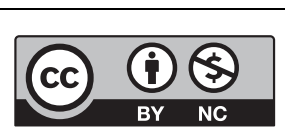

This work is licensed under a Creative Commons Attribution-NonCommercial 4.0 International License. 
Table 1 Demographic, clinical and biochemical characteristics of the study population.

\begin{tabular}{|c|c|c|}
\hline & No treatment group & Treatment group \\
\hline$N$ & 116 & 102 \\
\hline Age (years) & $45.1(13.7)$ & $47.0(11.4)$ \\
\hline BMI $\left(\mathrm{kg} / \mathrm{m}^{2}\right)$ & $25.0(5.0)$ & $27.1(5.9)$ \\
\hline W/H (ratio) & $0.78(0.07)$ & $0.79(0.08)$ \\
\hline $\mathrm{DBP}(\mathrm{mmHg})$ & $71(9)$ & $69(9)$ \\
\hline $\mathrm{SBP}(\mathrm{mmHg})$ & $114(13)$ & $114(15)$ \\
\hline $\mathrm{TSH}(\mu \mathrm{IU} / \mathrm{mL})$ & $2.4(1.6)$ & $2.0(1.6)$ \\
\hline FT4 (pmol/L) & $14.0(2.6)$ & $15.5(2.4)$ \\
\hline T3 (ng/mL) & $1.1(0.2)$ & $1.0(0.2)$ \\
\hline Anti-TPO (U/L) & $343(341)$ & 433 (1014) \\
\hline Anti-TG (U/L) & $110(250)$ & $392(780)$ \\
\hline Glucose (mg/dL) & $96.5(29.3)$ & $96.6(29.2)$ \\
\hline hsCRP (mg/L) & $1.8(3.2)$ & $1.9(3.5)$ \\
\hline $\operatorname{TOS}(\mu \mathrm{mol} / \mathrm{L})$ & $421(238)$ & 509 (308) \\
\hline
\end{tabular}

Median value and interquartile range for the two groups. BMI, body mass index; DBP, diastolic blood pressure; SBP, systolic blood pressure; TOS, total oxidative status; $\mathrm{W} / \mathrm{H}$, waist to hip ratio.

group (Mann-Whitney test, $P=0.039$ ). Smoking habits and hours of exercise did not differ between the two groups and had no effect on TOS levels. Fourteen women had type 2 diabetes and were equally distributed between the two groups. HsCRP levels did not differ between the two groups.

Figure 1 shows the percentage of women with 'high TOS' $(\geq 590 \mu \mathrm{mol} / \mathrm{L})$ depending on the weekly consumption of fruit (A) and vegetables (B). The significance of the chi-square for trends proves that there is a linear-by-linear association between fruit and vegetable consumption and TOS levels. The reduction of the portions of fruit and vegetables consumed is associated with higher probability of the appearance of 'high TOS'. Visual inspection of Fig. 1 reveals the best cutoffs for fruit (more than 14 portions weekly equals to more than two portions daily named as 'normal' vs less than 14 portions weekly equals to less than two portions daily named as 'low') and vegetable consumption (more than seven portions weekly equals to more than one portions daily named as 'daily' vs less than seven portions weekly equals to less than one portion daily named as 'sporadic'). These cutoffs were confirmed by ROC analysis. The cutoff of normal vs low fruit consumption for the prediction of 'high TOS' has a sensitivity of 73.9\% and a specificity of $51.3 \%$. The cutoff of daily vs sporadic vegetable consumption for the prediction of 'high TOS' has a sensitivity of $74.6 \%$ and a specificity of $48.4 \%$.

The chi-square for trends did not achieve statistical significance regarding the association with TOS levels and the weekly consumption of meat $(P=0.833)$, seafood $(P=0.402)$, dairy products $(P=0.523)$, alcohol $(P=0.059)$, coffee $(P=0.495)$ and tea $(P=0.057)$.

http://www.endocrineconnections.org

https://doi.org/10.1530/EC-18-0272

(c) 2018 The authors Published by Bioscientifica Ltd
Figure 2 shows the percentage of women with 'high TOS' ( $\geq 590 \mu \mathrm{mol} / \mathrm{L})$ depending on thyroxine treatment (a), BMI (b), fruit consumption (c) and vegetable consumption (d). 'High TOS' was more frequent in the treatment group compared to the no treatment group $(31.4 \%$ vs $14.7 \%$, $\mathrm{OR}=2.7$, 95\% CI: 1.4-5.2, Fig. 2A). The prevalence of 'high TOS' was higher among overweight and obese women compared to women with normal BMI $(30.4 \%$ vs $12.5 \%$, OR=3.1, 95\% CI: 1.5-6.4, Fig. 2B). Regarding dietary habits, low fruit consumption was associated with increased 'high TOS' prevalence compared to normal fruit consumption $(30.6 \%$ vs $12.9 \%$, OR=3.0, 95\% CI: $1.4-6.2$, Fig. 2C). Sporadic vegetable consumption was associated with increased 'high TOS' prevalence compared to daily consumption $(29.9 \%$ vs $13.5 \%, \mathrm{OR}=2.7,95 \% \mathrm{CI}$ : $1.3-5.7$, Fig. 2D). Overall, Fig. 2 shows that all four risk factors have roughly comparable effect on TOS. The OR values around three mean that the ratio of 'high TOS' to 'medium/low TOS' among women with the risk factor is about three
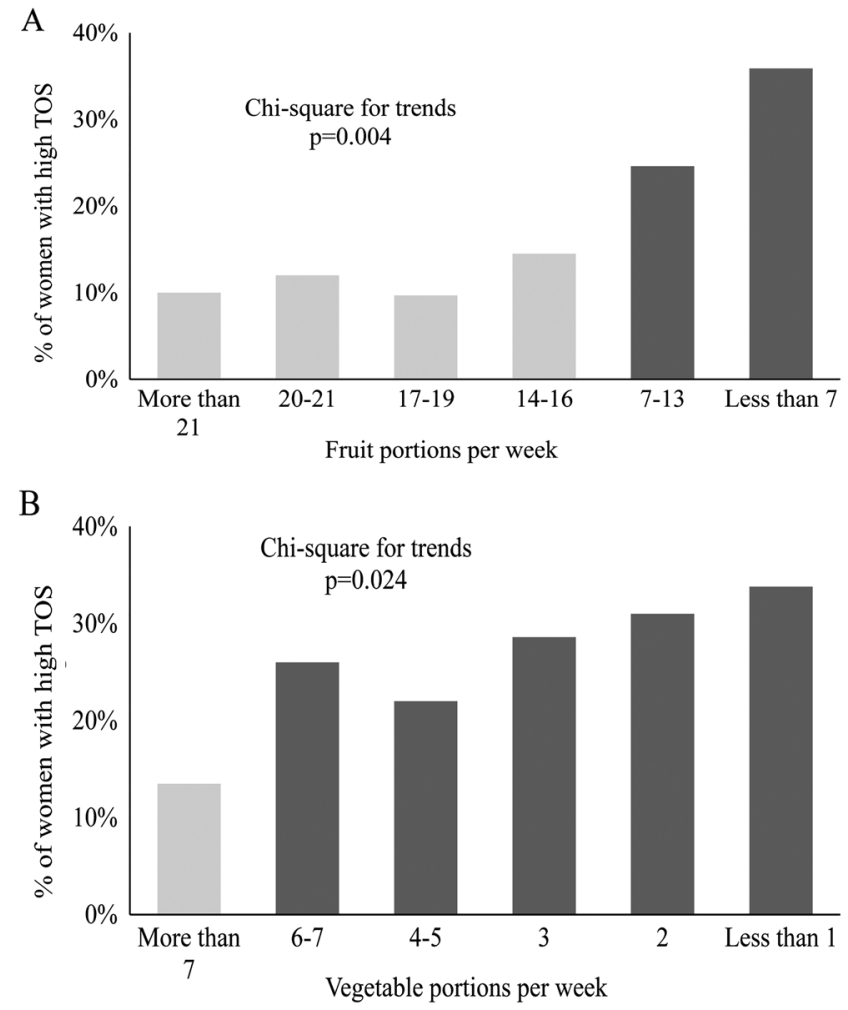

Figure 1

Percentage of women with 'high TOS' ( $\geq 590 \mu \mathrm{mol} / \mathrm{L}$ ) depending on the weekly consumption of fruit (A) and vegetables (B). The frequency distributions were tested for significance of linear-by-linear associations using the chi-square for trends statistic. In (A), the light shaded bars denote normal fruit consumption and the dark shaded bars denote low fruit consumption. In (B), the light shaded bars denote daily consumption of vegetables and the dark shaded bars denote sporadic consumption of vegetables.

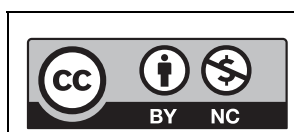

This work is licensed under a Creative Commons Attribution-NonCommercial 4.0 International License. 
B
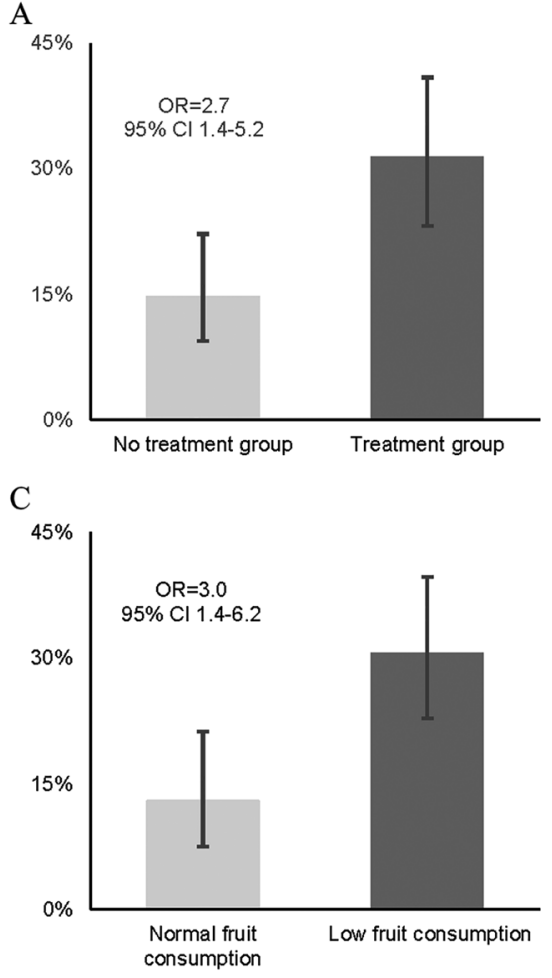

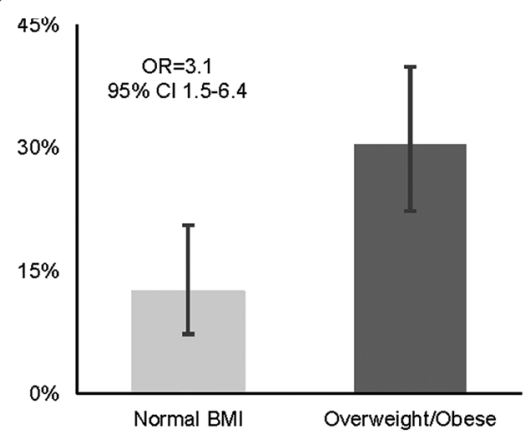

D

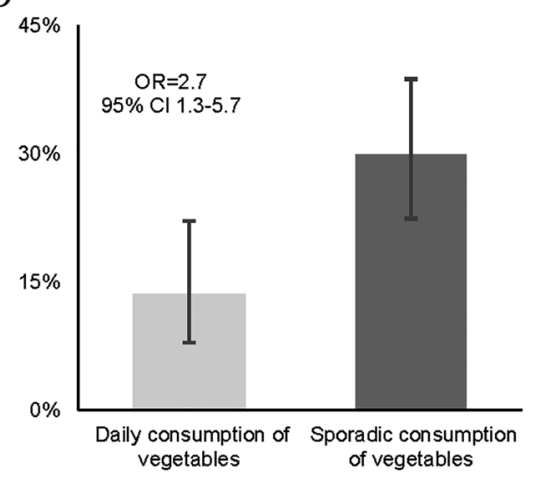

Figure 2

Percentage of women with 'high TOS' $(\geq 590 \mu \mathrm{mol} / \mathrm{L}$ ) depending on thyroxine treatment (31.4\% vs $14.7 \%$, OR $=2.7,95 \% \mathrm{Cl}: 1.4-5.2, \mathrm{~A}$ ), BMI (overweight or obese vs normal BMI, 30.4\% vs $12.5 \%$, OR $=3.1,95 \% \mathrm{Cl}: 1.5-6.4, \mathrm{~B})$, fruit consumption (low vs normal fruit consumption $30.6 \%$ vs $12.9 \%, \mathrm{OR}=3.0,95 \% \mathrm{Cl}: 1.4-6.2, \mathrm{C}$ ) and vegetable consumption (sporadic vs daily vegetable consumption $29.9 \%$ vs $13.5 \%$, OR $=2.7$, $95 \% \mathrm{Cl}: 1.3-5.7, \mathrm{D})$. The association was checked with $2 \times 2$ contingency tables reporting the OR with its associated $95 \%$ confidence intervals. The level of significance was set at 0.05 . TOS, total oxidative status. times than the same ratio among women without the risk factor.

Stepwise logistic regression showed that all four factors (thyroxine treatment, BMI, fruit and vegetable consumption) were significant independent predictors of 'high TOS' (Table 2). In each case, the related OR signifies how many times the odds of 'high TOS' to 'medium/ low TOS' are multiplied in the presence of the risk factor against the baseline of the absence of the risk factor.

Figure 3 exemplifies the additive effect of the presence of the examined risk factors on the development of 'high TOS'. It takes at least the conjoint effect of any three risk factors to increase significantly the probability of high TOS levels. Nonetheless, even the presence of all four risk factors cannot completely qualify the appearance of high TOS levels.

\section{Discussion}

The aim of the present study was to investigate the influence of thyroxine treatment, obesity and dietary habits on the development of high oxidative stress in euthyroid women with HT. The current findings revealed that 'high TOS' was more prevalent in women with HT who were on thyroxine replacement therapy compared to those without. 'High TOS' was also more frequent in overweight and obese women compared to those with

$$
\begin{array}{lr}
\text { http://www.endocrineconnections.org } & \text { ( ) } 2018 \text { The authors } \\
\text { https://doi.org/10.1530/EC-18-0272 } & \text { Published by Bioscientifica Ltd }
\end{array}
$$

normal BMI. In addition, limited consumption of fruit and vegetables was also associated with increased risk of 'high TOS'. The examined risk factors were independent and additive in their effect on TOS. It takes the coincident presence of at least three risk factors for the likelihood of 'high TOS' to be significantly elevated.

'High TOS' was more frequent in euthyroid women with HT who were on thyroxine replacement therapy. Studies in euthyroid patient with HT showed that the oxidative balance in these patients is shifted toward the oxidant side $(20,21,22)$. Also, there are few studies that showed an association between high oxidative stress and the progression of HT $(23,34,35)$. In the same direction,

Table 2 Results of the stepwise logistic regression of the

\begin{tabular}{|c|c|c|c|c|c|c|}
\hline $\begin{array}{l}\text { Independent } \\
\text { predictor }\end{array}$ & $\boldsymbol{B}$ & Wald & $d f$ & $\boldsymbol{P}$ & OR $\left(e^{B}\right)$ & $95 \% \mathrm{Cl}$ \\
\hline Treatment & 1.3 & 9.64 & 1 & 0.002 & 3.6 & $1.6-8.0$ \\
\hline $\mathrm{BMI}$ & 0.9 & 5.33 & 1 & 0.021 & 2.5 & $1.2-5.6$ \\
\hline $\begin{array}{l}\text { Fruit } \\
\text { consumption }\end{array}$ & 1.2 & 7.36 & 1 & 0.007 & 3.2 & $1.4-7.3$ \\
\hline $\begin{array}{l}\text { Vegetable } \\
\text { consumption }\end{array}$ & 0.8 & 3.89 & 1 & 0.049 & 2.3 & $1.1-5.3$ \\
\hline
\end{tabular}
effect of the four independent predictors (thyroxine treatment, BMI, fruit and vegetable consumption) on 'high TOS'.

BMI, body mass index; TOS, total oxidative status.

This work is licensed under a Creative Commons Attribution-NonCommercial 4.0 International License. 


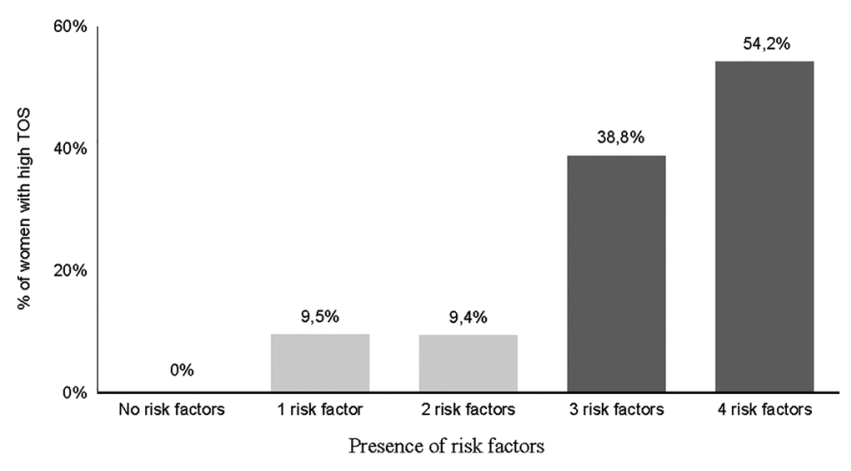

Figure 3

Percentage of women with 'high TOS' ( $\geq 590 \mu \mathrm{mol} / \mathrm{L}$ ) depending on the additive presence of risk factors. Chi-square for trends $=29.5, d f=1$, $P<0.001$. TOS, total oxidative status.

the present finding showed that women with HT who were in need of thyroxine replacement therapy to be euthyroid had higher oxidative stress levels compared to those who were euthyroid without therapy. The need of thyroxine replacement therapy to achieve euthyroidism shows that HT was more severe and thyroid function was more impaired in these women. Moreover, none of the women in the present study was newly diagnosed and all of them were euthyroid at the time of the study; this fact may explain the diversity in the findings from those in studies concerning the effect of thyroxine replacement therapy on oxidative status of HT patients $(32,33)$. We should note that studying only one parameter of oxidative stress is an important limitation of this study.

The prevalence of 'high TOS' was found to be higher among overweight and obese women compared to women with normal BMI. This finding is in accordance with studies about the oxidative status in obese population. These studies have shown that both obesity and obesityderived complications promote the generation of oxidative stress $(43,44,45,46,47)$. Some of the conditions that contribute to the increased oxidative stress in obesity are chronic low-grade inflammation, insulin resistance, hyperglycemia, elevated lipid levels, vitamin and mineral deficiencies, hyperleptinemia increased muscle activity, endothelial dysfunction and impaired mitochondrial function $(44,45,46,47)$. In addition, health problems caused by obesity such as type 2 diabetes, cardiovascular disease, systemic arterial hypertension, liver and renal dysfunction, carcinogenesis and respiratory disorders are associated with elevated oxidative stress levels $(45,46,47)$.

Another finding of the present study was that limited daily consumption of fruit and vegetables was associated with increased risk of high oxidative stress levels. The benefits of regular consumption of fruits and vegetables on human health are well established (48). Fruit and vegetables have high antioxidant capacity (40, $41,42)$; their addition to the daily diet reinforces the antioxidant defense system (49). Furthermore, the finding that all four factors examined in this study (thyroxine treatment, BMI, fruit and vegetable consumption) were significant independent predictors of 'high TOS', implies that following a healthy way of life (normal BMI, daily consumption of fruit and vegetables) contributes to maintaining low oxidative stress levels in this population as well.

There are, however, several important limitations in our study. The sample size of the study was relatively small. Moreover, we studied only one of the many parameters of oxidative stress. Unfortunately, we had no access to measure other oxidative stress indices. One further limitation of the present study was that the food frequency questionnaire that was developed for this study was not cross-validated, which prevents generalization of the present findings. In addition, the use of non-validated FFQ didn't allow estimation of total energy intake and therefore energy-adjusted consumption of foods and beverages has not been used. Finally, self-reported dietary intake has many limitations like recall and memory bias. Also, the FFQ is subjected to a number of limitations compared to other self-reported tools like $24 \mathrm{~h}$ recalls and food diaries. Some of these limitations include, but are not limited to, absence of details regarding dietary intake and reported inaccuracies originated from the use of a predefined list of food items, as well as memory bias and respondent bias according to social desirability (50). Further studies are warranted to validate the present findings.

In conclusion, oxidative stress was found increased in euthyroid women with HT under thyroxine replacement therapy. Nevertheless, a normal BMI and daily consumption of fruit and vegetables, all contribute in maintaining low oxidative stress levels. The findings of the present study suggest that patients with HT should be encouraged to modify their diet and achieve a healthy BMI.

\section{Declaration of interest}

The authors declare that there is no conflict of interest that could be perceived as prejudicing the impartiality of the research reported.

\section{Funding}

This research did not receive any specific grant from any funding agency in the public, commercial or not-for-profit sector.

$$
\begin{aligned}
& \text { http://www.endocrineconnections.org } \\
& \text { https://doi.org/10.1530/EC-18-0272 }
\end{aligned}
$$




\section{References}

1 Sies H, Berndt C \& Jones DP. Oxidative stress. Annual Review of Biochemistry 201786 715-748. (https://doi.org/10.1146/annurevbiochem-061516-045037)

2 McCord JM. The evolution of free radicals and oxidative stress. American Journal of Medicine 2000108 652-659. (https://doi. org/10.1016/S0002-9343(00)00412-5)

3 Valko M, Leibfritz D, Moncol J, Cronin MT, Mazur M \& Telser J. Free radicals and antioxidants in normal physiological functions and human disease. International Journal of Biochemistry and Cell Biology 200739 44-84. (https://doi.org/10.1016/j.biocel.2006.07.001)

4 Birben E, Sahiner UM, Sackesen C, Erzurum S \& Kalayci O. Oxidative stress and antioxidant defense. World Allergy Organization Journal 20125 9-19. (https://doi.org/10.1097/WOX.0b013e3182439613)

5 Aseervatham GS, Sivasudha T, Jeyadevi R \& Arul Ananth D. Environmental factors and unhealthy lifestyle influence oxidative stress in humans - an overview. Environmental Science and Pollution Research International 201320 4356-4369. (https://doi.org/10.1007/ s11356-013-1748-0)

6 Bjørklund G \& Chirumbolo S. Role of oxidative stress and antioxidants in daily nutrition and human health. Nutrition 201733 311-321. (https://doi.org/10.1016/j.nut.2016.07.018)

7 Vetrani C, Costabile G, Di Marino L \& Rivellese AA. Nutrition and oxidative stress: a systematic review of human studies. International Journal of Food Sciences and Nutrition 201364 312-326. (https://doi. org/10.3109/09637486.2012.738651)

8 Gomes-Rochette NF, Da Silveira Vasconcelos M, Nabavi SM, Mota EF, Nunes-Pinheiro DC, Daglia M \& De Melo DF. Fruit as potent natural antioxidants and their biological effects. Current Pharmaceutical Biotechnology 201617 986-993. (https://doi.org/10.2174/1389201017 $666160425115401)$

9 He F, Li J, Liu Z, Chuang CC, Yang W \& Zuo L. Redox mechanism of reactive oxygen species in exercise. Frontiers in Physiology 20167486

10 Finkler M, Lichtenberg D \& Pinchuk I. The relationship between oxidative stress and exercise. Journal of Basic and Clinical Physiology and Pharmacology 201425 1-11. (https://doi.org/10.1515/jbcpp2013-0082)

11 Bartfay W \& Bartfay E. A case-control study examining the effects of active versus sedentary lifestyles on measures of body iron burden and oxidative stress in postmenopausal women. Biological Research for Nurses 201416 38-45. (https://doi.org/10.1177/1099800413501717)

12 Poncin S, Gérard AC, Boucquey M, Senou M, Calderon PB, Knoops B, Lengelé B, Many MC \& Colin IM. Oxidative stress in the thyroid gland: from harmlessness to hazard depending on the iodine content. Endocrinology 2008149 424-433. (https://doi.org/10.1210/ en.2007-0951)

13 Poncin S, Van Eeckoudt S, Humblet K, Colin IM \& Gérard AC. Oxidative stress: a required condition for thyroid cell proliferation. American Journal of Pathology 2010176 1355-1363. (https://doi. org/10.2353/ajpath.2010.090682)

14 Carvalho DP \& Dupuy C. Role of the NADPH oxidases DUOX and NOX4 in thyroid oxidative stress. European Thyroid Journal 20132 160-167. (https://doi.org/10.1159/000354745)

15 Ohye H \& Sugawara M. Dual oxidase, hydrogen peroxide and thyroid diseases. Experimental Biology and Medicine 2010235 424-433. (https://doi.org/10.1258/ebm.2009.009241)

16 Wang D, Feng JF, Zeng P, Yang YH, Luo J \& Yang YW. Total oxidant/ antioxidant status in sera of patients with thyroid cancers. EndocrineRelated Cancer 201118 773-782. (https://doi.org/10.1530/ERC-110230)

17 Xing M. Oxidative stress: a new risk factor for thyroid cancer. Endocrine-Related Cancer 201219 7-11. (https://doi.org/10.1530/ERC11-0360)
18 Marcocci C, Leo M \& Altea MA. Oxidative stress in Graves' disease. European Thyroid Journal 20121 80-87. (https://doi. org/10.1159/000337976)

19 Zarković M. The role of oxidative stress on the pathogenesis of Graves' disease. Journal of Thyroid Research 20122012302537. (https://doi.org/10.1155/2012/302537)

20 Ruggeri RM, Vicchio TM, Cristani M, Certo R, Caccamo D, Alibrandi A, Giovinazzo S, Saija A, Campennì A, Trimarchi F, et al. Oxidative stress and advanced glycation end products in Hashimoto's thyroiditis. Thyroid 201626 504-511. (https://doi. org/10.1089/thy.2015.0592)

21 Baser H, Can U, Baser S, Yerlikaya FH, Aslan U \& Hidayetoglu BT. Assesment of oxidative status and its association with thyroid autoantibodies in patients with euthyroid autoimmune thyroiditis Endocrine 201548 916-923. (https://doi.org/10.1007/s12020-0140399-3)

22 Korkmaz H, Tabur S, Ozkaya M, Oguz E, Elboga U, Aksoy N \& Akarsu E. Paraoxonase and arylesterase levels in autoimmune thyroid diseases. Redox Report 201621 227-231. (https://doi.org/10.1080/135 10002.2015.1107310)

23 Ates I, Yilmaz FM, Altay M, Yilmaz N, Berker D \& Güler S. The relationship between oxidative stress and autoimmunity in Hashimoto's thyroiditis. European Journal of Endocrinology 2015173 791-799. (https://doi.org/10.1530/EJE-15-0617)

24 Metwalley KA, Farghaly HS, Saad K \& Othman HA. Oxidative status in children and adolescents with autoimmune thyroiditis. Clinical and Experimental Medicine 201616 571-575. (https://doi.org/10.1007/ s10238-015-0386-x)

25 Rostami R, Aghasi MR, Mohammadi A \& Nourooz-Zadeh J. Enhanced oxidative stress in Hashimoto's thyroiditis: inter-relationships to biomarkers of thyroid function. Clinical Biochemistry $2013 \mathbf{4 6}$ 308-312. (https://doi.org/10.1016/j.clinbiochem.2012.11.021)

26 Öztürk Ü, Vural P, Özderya A, Karadağ B, Doğru-Abbasoğlu S \& Uysal M. Oxidative stress parameters in serum and low density lipoproteins of Hashimoto's thyroiditis patients with subclinical and overt hypothyroidism. International Immunopharmacology 201214 349-352. (https://doi.org/10.1016/j.intimp.2012.08.010)

27 Hollowell JG, Staehling NW, Flanders WD, Hannon WH, Gunter EW, Spencer CA \& Braverman LE. Serum TSH, T(4), and thyroid antibodies in the United States population (1988 to 1994): National Health and Nutrition Examination Survey (NHANES III). Journal of Clinical Endocrinology and Metabolism 200287 489-499. (https://doi. org/10.1210/jcem.87.2.8182)

28 McLeod DS \& Cooper DS. The incidence and prevalence of thyroid autoimmunity. Endocrine 201242 252-265. (https://doi.org/10.1007/ s12020-012-9703-2)

29 Dong YH \& Fu DG. Autoimmune thyroid disease: mechanism, genetics and current knowledge. European Review of Medical and Pharmacological Sciences 201418 3611-3618.

30 Effraimidis G \& Wiersinga WM. Mechanisms in endocrinology: autoimmune thyroid disease: old and new players. European Journal of Endocrinology 2014170 241-252. (https://doi.org/10.1530/EJE-140047)

31 Wiersinga WM. Clinical relevance of environmental factors in the pathogenesis of autoimmune thyroid disease. Endocrinology and Metabolism 201631 213-222. (https://doi.org/10.3803/ EnM.2016.31.2.213)

32 Erdamar H, Demirci H, Yaman H, Erbil MK, Yakar T, Sancak B, Elbeg S, Biberoğlu G \& Yetkin I. The effect of hypothyroidism, hyperthyroidism, and their treatment on parameters of oxidative stress and antioxidant status. Clinical Chemistry and Laboratory Medicine 200846 1004-1010. (https://doi.org/10.1515/ CCLM.2008.183)

33 Ates I, Altay M, Yilmaz FM, Topcuoglu C, Yilmaz N, Berker D \& Guler S. The impact of levothyroxine sodium treatment on oxidative 
stress in Hashimoto's thyroiditis. European Journal of Endocrinology 2016174 727-734. (https://doi.org/10.1530/EJE-15-1061)

34 Ates I, Arikan MF, Altay M, Yilmaz FM, Yilmaz N, Berker D \& Guler S. The effect of oxidative stress on the progression of Hashimoto's thyroiditis. Archives of Physiology and Biochemistry 201729 1-6. (https://doi.org/10.1080/13813455.2017.1408660)

35 Giannakou M, Saltiki K, Mantzou E, Loukari E, Philippou G, Terzidis K, Lili K, Stavrianos C, Kyprianou M \& Alevizaki M. RAGE polymorphisms and oxidative stress levels in Hashimoto's thyroiditis. European Journal of Clinical Investigation 201747 341-347. (https:// doi.org/10.1111/eci.12739)

36 Sikaris KA. The clinical biochemistry of obesity. Clinical Biochemist Reviews 200425 165-181.

37 Schimke I, Müller J, Priem F, Kruse I, Schön B, Stein J, Kunze R, Wallukat G \& Hetzer R. Decreased oxidative stress in patients with idiopathic dilated cardiomyopathy one year after immunoglobulin adsorption. Journal of the American College of Cardiology 200138 178-183. (https://doi.org/10.1016/S0735-1097(01)01309-2)

38 Reichenbach J, Schubert R, Schindler D, Müller K, Böhles H $\&$ Zielen S. Elevated oxidative stress in patients with ataxia telangiectasia. Antioxidants and Redox Signaling 20024 465-469. (https://doi.org/10.1089/15230860260196254)

39 Tyrovolas S, Pounis G, Bountziouka V, Polychronopoulos E \& Panagiotakos DB. Repeatability and validation of a short, semiquantitative food frequency questionnaire designed for older adults living in Mediterranean areas: the MEDIS-FFQ. Journal of Nutrition for Elderly 201029 311-324. (https://doi.org/10.1080/01639366.2010.49 9096)

40 Pellegrini N, Serafini M, Salvatore S, Del Rio D, Bianchi M \& Brighenti F. Total antioxidant capacity of spices, dried fruits, nuts, pulses, cereals and sweets consumed in Italy assessed by three different in vitro assays. Molecular Nutrition and Food Research 2006 50 1030-1038. (https://doi.org/10.1002/mnfr.200600067)

41 Pellegrini N, Serafini M, Colombi B, Del Rio D, Salvatore S, Bianchi M $\&$ Brighenti F. Total antioxidant capacity of plant foods, beverages and oils consumed in Italy assessed by three different in vitro assays. Journal of Nutrition 2003133 2812-2819. (https://doi.org/10.1093/ jn/133.9.2812)
42 Carlsen MH, Halvorsen BL, Holte K, Bøhn SK, Dragland S, Sampson L, Willey C, Senoo H, Umezono Y, Sanada C, et al. The total antioxidant content of more than 3100 foods, beverages, spices, herbs and supplements used worldwide. Nutrition Journal 201093. (https://doi.org/10.1186/1475-2891-9-3)

43 Khan NI, Naz L \& Yasmeen G. Obesity: an independent risk factor for systemic oxidative stress. Pakistan Journal of Pharmaceutical Sciences 200619 62-65.

44 Fernández-Sánchez A, Madrigal-Santillán E, Bautista M, EsquivelSoto J, Morales-González A, Esquivel-Chirino C, Durante-Montiel I, Sánchez-Rivera G, Valadez-Vega C \& Morales-González JA. Inflammation, oxidative stress, and obesity. International Journal of Molecular Sciences 201112 3117-3132. (https://doi.org/10.3390/ ijms12053117)

45 Manna P \& Jain SK. Obesity, oxidative stress, adipose tissue dysfunction, and the associated health risks: causes and therapeutic strategies. Metabolic Syndrome and Related Disorders 201513 423-444. (https://doi.org/10.1089/met.2015.0095)

46 Marseglia L, Manti S, D'Angelo G, Nicotera A, Parisi E, Di Rosa G, Gitto E \& Arrigo T. Oxidative stress in obesity: a critical component in human diseases. International Journal of Molecular Sciences 201416 378-400. (https://doi.org/10.3390/ijms16010378)

47 Savini I, Catani MV, Evangelista D, Gasperi V \& Avigliano L. Obesityassociated oxidative stress: strategies finalized to improve redox state. International Journal of Molecular Sciences 201314 10497-10538. (https://doi.org/10.3390/ijms140510497)

48 Slavin JL \& Lloyd B. Health benefits of fruits and vegetables. Advances in Nutrition 20123 506-516. (https://doi.org/10.3945/ an.112.002154)

49 Dragsted LO, Pedersen A, Hermetter A, Basu S, Hansen M, Haren GR, Kall M, Breinholt V, Castenmiller JJ, Stagsted J, et al. The 6-a-day study: effects of fruit and vegetables on markers of oxidative stress and antioxidative defense in healthy nonsmokers. American Journal of Clinical Nutrition 200479 1060-1072. (https://doi.org/10.1093/ ajcn/79.6.1060)

50 Pérez Rodrigo C, Aranceta J, Salvador G \& Varela-Moreiras G. Food frequency questionnaires. Nutrition Hospitalaria 201531 49-56. (https://doi.org/10.3305/nh.2015.31.sup3.8751)

Received in final form 13 July 2018

Accepted 6 August 2018

Accepted Preprint published online 8 August 2018 http://www.endocrineconnections.org https://doi.org/10.1530/EC-18-0272 (c) 2018 The authors Published by Bioscientifica Ltd

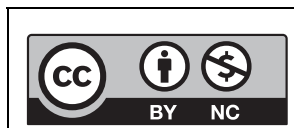

This work is licensed under a Creative Commons Attribution-NonCommercial 4.0 International License. 